\title{
Indoor Air Pollution Related Respiratory Ill Health, a Sequel of Biomass Use
}

\author{
David Mulenga ${ }^{a^{*}}$, Seter Siziya ${ }^{\text {a }}$ \\ ${ }^{a}$ Copperbelt University, Michael Chilufya Sata School of Medicine, Ndola, Zambia.
}

Received 02 January 2019; Accepted 24 February 2019

\begin{abstract}
Introduction: Climate change may worsen existing indoor air problems and create new problems by altering outdoor conditions that affect indoor conditions. Since climate change is due to both natural variability and human-induced contributions, public health professionals through their expertise in health promotion and behavior change can play a vital role in promoting lifestyle choices that will decrease greenhouse gas emissions. This study, therefore, aims at presenting the health effects of indoor air pollutants from biomass use. Methods: A cross sectional study involving 1,170 consenting women was conducted in Masaiti and Ndola districts of Zambia. Data collection tools included a structured questionnaire; foobot (indoor air quality monitoring device) and spirometer (lung function test device). Data was analyzed using SPSS version 16 and analyses were done at Univariate, bivariate and multivariate level at 5\% statistical significant level. Results: Population using biomass as cooking fuel was 69.2\%. Indoor particulate (PM2.5) overall median (Q1, Q2) distribution during cooking period was $501(411,686) \mu \mathrm{g} / \mathrm{m}^{3}$ and daily average was $393(303,578) \mu \mathrm{g} / \mathrm{m}^{3}$ while VOC daily average was $343(320,363) \mathrm{ppb}$. The proportion of women with respiratory symptoms and impaired lung functions was higher in households with high levels of indoor pollutants. There was a statistically significant association between mean indoor particulate concentration levels and the number of maternal respiratory symptoms. There was a significant association between indoor VOC and forced vital capacity $(\mathrm{p}=0.011)$. Conclusion: The results contribute to the growing evidence regarding the effect of biomass use on indoor air quality and consequent adverse respiratory health outcomes.
\end{abstract}

Keywords: Particulate Matter; Volatile Organic Compounds; Biomass.

\section{Introduction}

Natural variability and human activities have been implicated for climate change. The scale of environmental health problems as a result of climate change has expanded from household irritants, to global level. According to research, climate change may worsen existing indoor air problems and create new problems by altering outdoor conditions that affect indoor conditions. Climate change can also lead to changes in the mixing of outdoor and indoor air. Reduced mixing of outdoor and indoor air limits penetration of outdoor pollutants into the indoors, but also leads to higher concentrations of pollutants generated indoors since their dilution by outdoor air is decreased [1].

Climate change may alter the indoor concentrations of pollutants generated outdoors such as ground-level ozone, particulate matter, and aeroallergens such as pollen. Changes in the climate may also increase pollutants generated indoors, such as mold and volatile organic compounds. Whether outdoors or indoors, poor air quality, can affect negatively the human respiratory and cardiovascular systems. Most of the air people breathe over their lifetimes will be indoors, since people spend the vast majority of their time in indoor environments. Thus, alterations in indoor air pollutant concentrations from climate change have important health implications. That is why Brazil and India have

* Corresponding author: davykdn@gmail.com

$>$ This is an open access article under the CC-BY license (https://creativecommons.org/licenses/by/4.0/).

(C) Authors retain all copyrights. 
substantially expanded the use of liquefied petroleum gas (LPG) in their household energy mix. The net climate impact of this approach compared to current biomass stoves is minimal or non-existent, and the social and health benefits are, in contrast, potentially great [2].

Current research indicates that the health impact resulting from direct exposure to biomass cook smoke leads to about 2.2-3.6 million excess deaths per year, accounting for about 3.9\%-6.4\% of global mortality (GBD 2015), making air pollution (household and ambient) the largest Environmental source of ill-health globally.

This study is designed to monitor indoor air quality (PM2.5 and VOC) and assess the association between the concentration levels and respiratory ill health. Research has demonstrated that decrease in pollution can improve lung function in both children and adults [3]. Children during periods of increasing PM regulation and therefore decreasing average PM concentrations. Investigators found higher FEV1 and FVC in the children exposed to the lowest concentrations of PM and, as air quality improved, the proportion of children with clinically low FEV1 subsequently declined [4]. Similarly, reductions in PM in an urban area of the Netherlands were associated with a $3 \%$ and $6 \%$ improvement in FEV1 and FVC, respectively, in both children and adults69. In the SAPALDIA study, a $10 \mu \mathrm{g} / \mathrm{m}^{3}$ decrease in PM10 concentration was associated with a 9\% decrease in the rate of yearly decline of FEV1 in over 9000 randomly selected Swiss adults [5]. These studies highlight that even modest reductions in PM can translate to meaningful improvements in lung function. As the EPA does not regulate the indoor environment, interventions to mitigate exposure to indoor PM are less well studied. A small number of research studies have shown improvements in indoor PM concentrations following behavioral modifications and use of indoor air cleaners [6-8].

Therefore, public health professionals through their expertise in health promotion and behavior change can play a vital role in promoting lifestyle choices that will decrease greenhouse gas emissions [9, 10]. This study, therefore, aims at presenting the health effects of biomass use one of the sequels of climate change impacts.

The precise mechanism as to how air pollutants such as particulate matter (PM2.5) may influence health and lung function is unknown. However, research suggests that PM may mediate adverse health effects via the generation of reactive oxygen species [11-13], activation of cell signaling pathways, and alterations of respiratory tract barrier function and antioxidant defenses, all of which may lead to airway inflammation and changes in pulmonary function [14]. Additionally, cellular changes resulting from PM exposure may cause epigenetic modifications, leading to alterations in gene expression [15].

\section{Methods}

A cross section study was conducted in rural (Masaiti) and urban (Ndola) areas of study population. This was a cross section study using quantitative methods and descriptive in nature.

\subsection{Study population}

Women were recruited from 9 health centres of the indigenous communities in rural (Masaiti) and urban (Ndola) compounds. A two stage sampling method was used to recruit respondents. In the first stage, health facilities were sampled using simple random sampling method based on ministry of Health $(\mathrm{MoH})$ Facility Listing as sampling frame. The second stage involved use of antenatal (ANC) registers and women were selected using systematic random sampling. Every third woman was considered for enrolment after a random start for each clinic.

\subsection{Assessment of Respiratory Symptoms and Lung Function}

Questionnaires recorded frequency and duration of respiratory symptoms including cough, phlegm, wheeze, and chest tightness experienced in the previous 6 months. The respiratory questionnaire was adapted from the standard respiratory questionnaire of the Centre for Environment and Respiratory Health, University of Oulu, Finland. Lung function test were conducted using the spirobank G SN A23-048.00000 (Italy) and the parameters of interest were $\mathrm{FEV}_{1}, \mathrm{FVC}$, and $\mathrm{FEV}_{1} / \mathrm{FVC}$ ratio.

\subsection{Exposure Assessment}

The primary measure of indoor air pollution was particulate matter of aerodynamic diameter $>2.5$ and volatile organic compounds (VOC). The measurement was conducted using a foobot FBT0002100 (China) and 24h average readings were obtained in households.

\subsection{Data Analysis}

Data was analyzed using SPSS version 20 and Mean concentrations, median distributions and standard deviations for PM2.5 and VOCs in $\mu \mathrm{g} / \mathrm{m} 3$ and ppb respectively were calculated. Comparisons of distributions of PM2.5 \& VOCs between health endpoints or rural and urban areas using Mann Whitney $U$ test and Kruskal Wallis test were 
performed. Multinomial logistic regression for associations and the relative risk ratios to determine the risk of having respiratory symptoms among women from households with varying levels of indoor air pollutants were conducted.

\section{Results}

\subsection{General Characteristics}

The study considered a sample size of 1,170 pregnant women of which the majority $(91.2 \%)$ were married with more than half $(54.6 \%)$ having attained secondary and only close to a third $(30.0 \%)$ primary education. More than two thirds $(69.6 \%)$ of the participants were unemployed and were mainly housewives. Hypertension and diabetes were not common and only 3.7 and $1.8 \%$ respectively were reported. Percentages of 19.7 and $3.1 \%$ constituted reports of alcohol use and cigarette smoking respectively.

\subsection{Exposure Variables}

Only less than $5 \%$ of the women reported not being involved in cooking duties during pregnancy. Charcoal was the main biomass fuel used in cooking followed by wood in the population (Table 1). Table 2 shows a summary of the various types of cooking environments reported in the rural and urban study population.

Table 1. Cooking fuel types of rural, urban and whole population

\begin{tabular}{ccccccc}
\hline \multirow{2}{*}{ Fuel type } & \multicolumn{2}{c}{ Rural } & \multicolumn{2}{c}{ Urban } & \multicolumn{2}{c}{ Total } \\
\cline { 2 - 7 } & $\mathbf{\%}$ & $\mathbf{9 5 \%} \mathbf{C I}$ & $\mathbf{\%}$ & $\mathbf{9 5 \%} \mathbf{C I}$ & $\mathbf{\%}$ & $\mathbf{9 5 \%} \mathbf{C I}$ \\
\hline Wood & 36 & $32.2-40.4$ & 8 & $6.2-10.2$ & 15 & $13.1-17.0$ \\
Crop residue & 4.3 & $2.4-6.0$ & 2 & $1.0-3.0$ & 2 & $1.4-3.1$ \\
Charcoal & 56 & $52.1-61.0$ & 51 & $47.3-55.0$ & 52 & $49.3-55.2$ \\
Electricity & 3.7 & $2.0-4.2$ & 16 & $13.1-18.4$ & 12 & $11.0-15.0$ \\
\hline
\end{tabular}

Table 2. Showing types of cooking environments in the rural and urban population of the study

\begin{tabular}{ccccccc}
\hline \multirow{2}{*}{ Kitchen type } & \multicolumn{2}{c}{ Rural } & \multicolumn{2}{c}{ Urban } & \multicolumn{2}{c}{ Total } \\
\cline { 2 - 7 } & $\mathbf{\%}$ & $\mathbf{9 5 \%} \mathbf{C I}$ & $\mathbf{\%}$ & $\mathbf{9 5 \%} \mathbf{C I}$ & $\mathbf{\%}$ & $\mathbf{9 5 \%} \mathbf{C I}$ \\
\hline Under a shed & 13 & $6.0-10.0$ & 8 & $6.1-9.2$ & 8.0 & $6.1-9.2$ \\
Semi-enclosed & 17 & $14.4-20.0$ & 17 & $15.0-19.2$ & 17.0 & $15.0-19.2$ \\
Enclosed & 43 & $34.3-41.4$ & 40.1 & $37.3-43.1$ & 40.1 & $37.3-43.1$ \\
Open space & 14.3 & $19.3-25.4$ & 20.3 & $18.0-23.0$ & 20.3 & $18.0-23.0$ \\
Living room & 1.2 & $1.0-3.0$ & 1.4 & $1.0-2.3$ & 1.4 & $1.0-2.3$ \\
Unclassified & 13.2 & $12.3-16.0$ & 14 & $11.0-16.3$ & 14.0 & $11.0-16.3$ \\
\hline
\end{tabular}

\subsection{PM2.5 and VOCs Monitoring}

Indoor PM2.5 varied between $79 \mu \mathrm{g} / \mathrm{m}^{3}$ and $921 \mu \mathrm{g} / \mathrm{m}^{3}$, with an overall mean (SD) for daily average of $444.5 \mu \mathrm{g} / \mathrm{m}^{3}$ (170.2) while VOCs the range was from $245 \mathrm{ppb}$ to $393 \mathrm{ppb}$ with an overall mean (SD) for daily average of $342 \mathrm{ppb}$ (25.3). The maximum readings were obtained during cooking time while the minimum before cooking period. Table 3 presents the overall median PM2.5 and VOC in the entire population while Table 4 is an indoor air pollution concentration index for PM2.5 and VOCs.

Table 3. Showing overall mean PM2.5 and VOCs in the whole population

\begin{tabular}{cc}
\hline Pollutants & Median $(\mathbf{Q 1}, \mathbf{Q 3})$ \\
\hline PM2.5 & \\
\hline During cooking & $501(411,686)$ \\
Daily average & $393(303,578)$ \\
\hline VOC & \\
\hline Daily average & $343(320,363)$ \\
\hline
\end{tabular}

The median $(\mathrm{Q} 1, \mathrm{Q} 2)$ recorded for the study population for PM2.5 during cooking activities and daily average were $501(411,686)$ and $393(303,578)$ while for VOCs daily average was 343(320, 363). 
Table 4. PM2.5 and VOC concentration index

\begin{tabular}{ccccccc}
\hline Period & PM2.5 $\left(\boldsymbol{\mu g} / \mathbf{m}^{\mathbf{3}}\right)$ & From & To & VOC $(\mathbf{p p b})$ & From & To \\
\hline \multirow{2}{*}{$\begin{array}{c}\text { Before } \\
\text { cooking }\end{array}$} & Low & 79 & 179 & Low & 245 & 320 \\
& Moderate & 180 & 344 & Moderate & 321 & 350 \\
& High & 345 & 664 & High & 351 & 383 \\
\hline \multirow{2}{*}{ During } & Low & 335 & 432 & Low & 297 & 322 \\
cooking & Moderate & 433 & 601 & Moderate & 323 & 353 \\
& High & 602 & 921 & High & 354 & 393 \\
\hline \multirow{2}{*}{ After } & Low & 262 & 369 & Low & 272 & 333 \\
cooking & Moderate & 370 & 535 & Moderate & 334 & 363 \\
& High & 536 & 855 & High & 364 & 393 \\
\hline \multirow{2}{*}{ Daily } & Low & 226 & 328 & Low & 300 & 325 \\
average & Moderate & 329 & 493 & Moderate & 326 & 355 \\
& High & 494 & 813 & High & 356 & 385 \\
\hline
\end{tabular}

\subsection{Maternal Respiratory Symptoms}

Cough was the main respiratory symptom among the participants followed by sputum then nasal symptoms. The rural area had more records of cough and sputum compared to the urban area.

Maternal respiratory symptoms and mean household air pollution (PM2.5 and VOC) concentration levels in rural and urban area.

Table 5. Presents the proportion of pregnant women with respiratory symptoms

\begin{tabular}{cccc}
\hline & Rural & Urban & Total \\
\hline Symptom & $\%$ & $\%$ & $\%$ \\
Cough & 79.4 & 69.0 & 72.0 \\
Sputum & 48.0 & 45.3 & 46.0 \\
Wheezing & 34.0 & 29.3 & 30.4 \\
Breathlessness & 17.3 & 16.0 & 16.3 \\
Nasal symptoms & 41.0 & 47.2 & 46.0 \\
Throat symptoms & 37.0 & 32.0 & 33.0 \\
\hline
\end{tabular}

Figure 1 shows that on average a PM2.5 of $311.3 \mu \mathrm{g} / \mathrm{m}^{3}$ in rural and $297.6 \mu \mathrm{g} / \mathrm{m}^{3}$ in urban areas has no effect on maternal respiratory symptoms. Impliedly an additional PM2.5 of $106.7 \mu \mathrm{g} / \mathrm{m}^{3}$ in rural areas and $74.7 \mu \mathrm{g} / \mathrm{m} 3 \mathrm{in} u \mathrm{rban}$ areas marks the onset of respiratory symptoms among exposed pregnant women. Therefore, exposing a pregnant woman to an indoor mean concentration of $418 \mu \mathrm{g} / \mathrm{m}^{3}$ in rural areas and $372.3 \mu \mathrm{g} / \mathrm{m}^{3}$ in urban areas increases the risk of having at least one respiratory symptom.

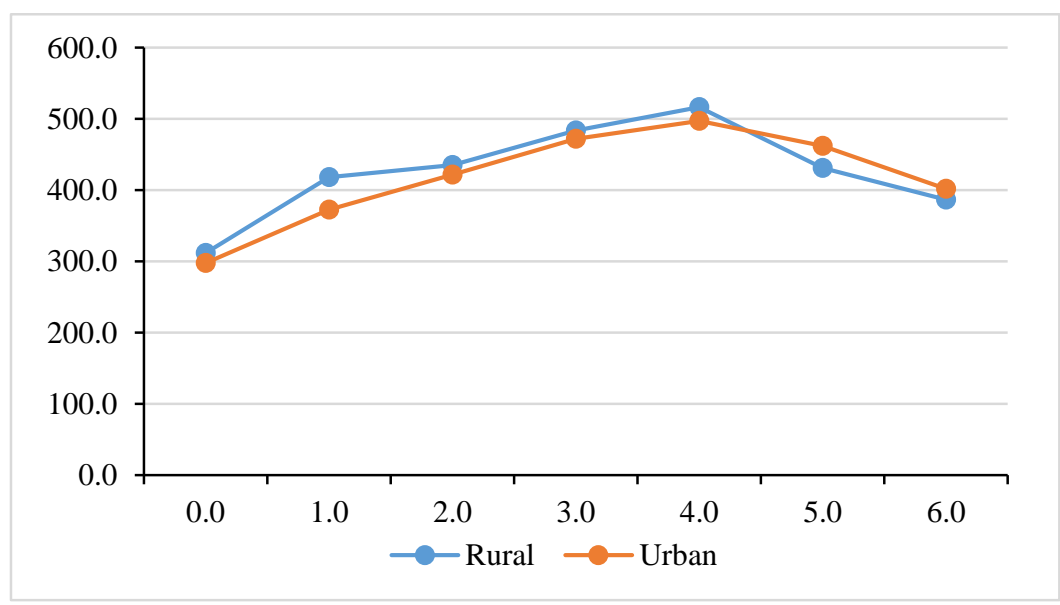

Figure 1. Number of maternal respiratory symptoms versus mean indoor concentration levels of particulate matter (micrograms) in rural and urban areas 
On average a PM2.5 of $311.3 \mu \mathrm{g} / \mathrm{m}^{3}$ in rural and $297.6 \mu \mathrm{g} / \mathrm{m}^{3}$ in urban areas has no effect on maternal respiratory symptoms. Impliedly an additional PM2.5 of $106.7 \mu \mathrm{g} / \mathrm{m}^{3}$ in rural areas and $74.7 \mu \mathrm{g} / \mathrm{m} 3$ in urban areas marks the onset of respiratory symptoms among exposed pregnant women. Therefore, exposing a pregnant woman to an indoor mean concentration of $418 \mu \mathrm{g} / \mathrm{m}^{3}$ in rural areas and $372.3 \mu \mathrm{g} / \mathrm{m}^{3}$ in urban areas increases the risk of having at least one respiratory symptom.

Table 6. Showing mean differences of indoor PM2.5 between participants with and those without respiratory symptoms in rural area

\begin{tabular}{ccc}
\hline Group & Mean (SD) & $\mathbf{9 5 \%}$ C.I \\
\hline Without MRS & $53.7(11.0)$ & $(45.2,62.1)$ \\
With MRS & $83.9(35.5)$ & $(80.7,87.2)$ \\
Combined & $83.4(35.4)$ & $(80.2,86.6)$ \\
diff & $-30.3(11.8)$ & $(-53.5,-7.1)$ \\
\hline p value $=$ & 0.011 & \\
\hline
\end{tabular}

After running an independent test to ascertain mean differences of PM2.5 and maternal respiratory symptoms, the findings indicate that there was a statistical significant mean difference in PM2.5 of those with respiratory symptoms and those without respiratory symptoms in both rural $(p$-value $=0.0109)$ and urban $(p$-value $<0.0001)$ area.

\subsection{Multinomial Logistic Regression}

Impact of HAP (PM2.5 and VOC) on the number of maternal respiratory symptoms.

There was a statistically significant association between mean indoor PM2.5 concentration levels and the number of maternal respiratory symptoms. However, mean indoor volatile organic compounds concentration levels did not show any significant association with the number of maternal respiratory health.

Table 7. Showing the association between maternal respiratory symptoms (MRS) and household air pollution (PM2.5 and VOC)

\begin{tabular}{|c|c|c|c|c|c|c|c|c|}
\hline & & \multicolumn{7}{|c|}{ Number of respiratory symptoms } \\
\hline & & $\mathbf{0}$ & 1 & 2 & 3 & 4 & 5 & 6 \\
\hline & PM25 & 1 & $1.04 *$ & $1.04 * *$ & $1.05^{* *}$ & $1.05^{* * *}$ & $1.04^{*}$ & 1.03 \\
\hline \multirow[t]{4}{*}{ Rural } & & & $(1.00-1.08)$ & $(1.00-1.08)$ & $(1.01-1.09)$ & $(1.01-1.10)$ & $(1.00-1.08)$ & $(0.98-1.08)$ \\
\hline & VOC & 1 & 1 & 1.02 & 1.03 & 1.01 & 1.01 & 1.07 \\
\hline & & & $(0.93-1.08)$ & $(0.95-1.09)$ & $(0.97-1.11)$ & $(0.94-1.08)$ & $(0.94-1.09)$ & $(0.97-1.19)$ \\
\hline & PM25 & 1 & $1.05 * * *$ & $1.06 * * *$ & $1.07 * * *$ & $1.07 * * *$ & $1.07 * * *$ & $1.05^{* * * *}$ \\
\hline \multirow[t]{3}{*}{ Urban } & & & $(1.01-1.08)$ & $(1.03-1.09)$ & $(1.04-1.10)$ & $(1.04-1.11)$ & $(1.03-1.10)$ & $(1.02-1.09)$ \\
\hline & VOC & 1 & 0.99 & 0.98 & 0.99 & 0.98 & $0.96^{*}$ & 1 \\
\hline & & & $(0.95-1.03)$ & $(0.95-1.02)$ & $(0.95-1.03)$ & $(0.94-1.03)$ & $(0.92-1.01)$ & $(0.93-1.08)$ \\
\hline
\end{tabular}

ciEform in parentheses $* * * \mathrm{p}<0.01, * * \mathrm{p}<0.05, * \mathrm{p}<0.1$

\section{Discussion}

This study is one of the first to evaluate household air pollution using PM2.5 and VOCs as indicators in Zambian houses. To the best of our knowledge it is the first study, to derive an optimal mean indoor PM2.5 threshold for detecting onset of respiratory symptoms in Zambia among pregnant women that cook predominantly with solid fuel. The current study found high indoor mean PM2.5 and VOCs concentration levels in both rural and urban areas of the study population. However, there seemed to be higher mean indoor concentration levels of PM2.5 and VOCs in households that used biomass only compared to those that used electricity. This result is in accord with what is pertaining in sub-Saharan Africa and similar findings elsewhere indicate that particulate matter levels may be 10-50 times higher than the recommended standards in houses where solid fuels are used [16]. Our study also observed more respiratory symptoms among women from households where biomass only was used as cooking fuel compared to women from households that used electricity. This finding is consistent with research results in randomized control trials in rural Mexico that indicated that cleaner fuels were significantly associated with a reduction of respiratory symptoms among women [17]. 
We found that there was a significant association between mean indoor PM2.5 concentration levels and onset of maternal respiratory symptoms. These findings are consistent with results elsewhere [18], indicating that even shortterm exposure to PM2.5 results increased risk for cardiovascular and respiratory hospital admissions and this is further confirmed by studies which indicate that even at relatively low levels respirable particulate exposure can increase respiratory symptoms and mortality $[19,20]$. Results in an Indian study also showed that increased respiratory symptoms are related to an increased indoor concentration levels of PM2.5 [21, 22]. The gases and particles are said to be responsible for weak host defenses against respiratory infections which would further lead to an increased predisposition to respiratory infections. Inflammation of the airways and alveoli, resulting from the exposure to these pollutants, may be another mechanism increasing the severity of respiratory infections [23].

A review of information relating to air pollution in Zambia indicate that there is paucity of such information because like in many countries in the sub-Saharan Africa, air monitoring is limited and there is a lack of air quality standards at national level. In our study, an indoor mean concentration of $418 \mu \mathrm{g} / \mathrm{m}^{3}$ in rural areas and $372.3 \mu \mathrm{g} / \mathrm{m}^{3}$ in urban areas was responsible for increasing the risk of having at least one respiratory symptom among pregnant women. This is comparable with previous studies conducted in Asia [24] stating that PM2.5 concentrations in houses get as high as over $2000 \mathrm{mg} / \mathrm{m}^{3}$ and in some African countries like Zimbabwe and Kenya where indoor air pollution monitoring has been conducted [23, 25]. The findings of our study show that indoor air pollution in our study population excessively exceed the WHO recommendations [26, 27].

This finding is an indication that Zambian urban and rural women will continue to carry the burden of air pollution-related morbidity and mortality if no public health interventions are implemented to control the poor environmental conditions which are fueled by limited air monitoring and lack of air quality standards at national level. Our current study creates an important baseline for the implementation of systematic PM2.5 data collection to enable air pollution-related respiratory health impact assessment among women predominantly using biomass for cooking. This will in turn help in the development of strategies and policies relating to air quality and respiratory health.

The promotion of gas and electricity as household fuels has not, until quite recently, been linked to the health agenda surrounding continued use of biomass. Primarily in India starting in 2015, but also beginning in a few other countries, however, there have recently been major government-led programs launched to enhance the use of LPG driven in large part by health concerns.

\section{Conclusion}

Household air pollution levels in Zambian homes are high. Further research work is required because the concentration levels that have been observed in this study are hazardous and are likely to be have adverse health outcomes. Public health interventions should therefore be identified to reduce indoor concentration levels to less harmful standards. The process of reducing concentration levels of PM2.5 is beyond the control of individuals and requires action by public authorities and health sector can play a pivotal role in leading a multi-sectoral approach to the prevention of exposure to air pollution by engaging and supporting other relevant sectors such as housing, industry and energy sectors in reducing the risk of indoor air pollution to respiratory health among women.

Therefore, since our intended goal to lower disease rates and health care costs, the practical way of responding to these challenges is to abide by the new WHO Indoor Air Quality Guidelines which among other issues recommend phasing out household kerosene and coal use, scaling-up production and use of the cleanest household fuels, including LPG, ethanol and biogas. The guidelines also recommend transitioning from inefficient biomass cookstoves to improved models with adequate venting. Small solar systems to power lights can be substitutes for kerosene lamps - in homes

\section{Declaration of Competing Interest}

The authors declare that they have no known competing financial interests or personal relationships that could have appeared to influence the work reported in this paper.

\section{References}

[1] Stephens, B., \& Siegel, J. A. (2012). Penetration of ambient submicron particles into single-family residences and associations with building characteristics. Indoor Air, 22(6), 501-513. doi:10.1111/j.1600-0668.2012.00779.x

[2] Goldemberg, J., Martinez-Gomez, J., Sagar, A., \& Smith, K. R. (2018). Household air pollution, health, and climate change: cleaning the air. Environmental Research Letters, 13(3), 030201. doi:10.1088/1748-9326/aaa49d.

[3] Gauderman, W. J., Urman, R., Avol, E., Berhane, K., McConnell, R., Rappaport, E., ... Gilliland, F. (2015). Association of Improved Air Quality with Lung Development in Children. New England Journal of Medicine, 372(10), $905-913$. doi:10.1056/nejmoa1414123. 
[4] García-Mozo, H., Galán, C., Jato, V., Belmonte, J., De La Guardia, C. D., Fernández, D., ... \& Trigo, M. M. (2006). Quercus pollen season dynamics in the Iberian Peninsula: response to meteorological parameters and possible consequences of climate change. Annals of Agricultural and Environmental Medicine, 13(2), 209.

[5] Garfin, G., G. Franco, H. Blanco, A. Comrie, P. Gonzalez, T. Piechota, R. Smyth, and R. Waskom, 2014: Ch. 20: Southwest. Climate Change Impacts in the United States: The Third National Climate Assessment, J.M. Melillo, Richmond, T. (T.C.), and Yohe, G.W., Eds., U.S. Global Change Research Program, 462-486.

[6] Halsby, K. D., Joseph, C. A., Lee, J. V., \& Wilkinson, P. (2014). The relationship between meteorological variables and sporadic cases of Legionnaires' disease in residents of England and Wales. Epidemiology \& Infection, 142(11), $2352-2359$. doi:10.1017/S0950268813003294.

[7] Haman, C. L., Couzo, E., Flynn, J. H., Vizuete, W., Heffron, B., \& Lefer, B. L. (2014). Relationship between boundary layer heights and growth rates with ground-level ozone in Houston, Texas. Journal of Geophysical Research: Atmospheres, 119(10), 6230-6245. doi:10.1002/2013jd020473.

[8] Henderson, S. B., Brauer, M., MacNab, Y. C., \& Kennedy, S. M. (2011). Three Measures of Forest Fire Smoke Exposure and Their Associations with Respiratory and Cardiovascular Health Outcomes in a Population-Based Cohort. Environmental Health Perspectives, 119(9), 1266-1271. doi:10.1289/ehp.1002288.

[9] Smith, K. R., Bruce, N., Balakrishnan, K., Adair-Rohani, H., Balmes, J., Chafe, Z., ... Rehfuess, E. (2014). Millions Dead: How Do We Know and What Does It Mean? Methods Used in the Comparative Risk Assessment of Household Air Pollution. Annual Review of Public Health, 35(1), 185-206. doi:10.1146/annurev-publhealth-032013-182356.

[10] Burnett, D., Barbour, E., \& Harrison, G. P. (2014). The UK solar energy resource and the impact of climate change. Renewable Energy, 71, 333-343. doi:10.1016/j.renene.2014.05.034.

[11] Janssen, N. A. H., Strak, M., Yang, A., Hellack, B., Kelly, F. J., Kuhlbusch, T. A. J., ... Hoek, G. (2014). Associations between three specific a-cellular measures of the oxidative potential of particulate matter and markers of acute airway and nasal inflammation in healthy volunteers. Occupational and Environmental Medicine, 72(1), 49-56. doi:10.1136/oemed-2014102303.

[12] Hogervorst, J. G. F., de Kok, T. M. C. M., Briedé, J. J., Wesseling, G., Kleinjans, J. C. S., \& van Schayck, C. P. (2006). Relationship between Radical Generation by Urban Ambient Particulate Matter and Pulmonary Function of School Children. Journal of Toxicology and Environmental Health, Part A, 69(3), 245-262. doi:10.1080/15287390500227431.

[13] Kelly, F. J., \& Fussell, J. C. (2012). Size, source and chemical composition as determinants of toxicity attributable to ambient particulate matter. Atmospheric Environment, 60, 504-526. doi:10.1016/j.atmosenv.2012.06.039.

[14] U.S. Environmental Protection Agency, Washington DC: Integrated science assessment for particulate matter. US Environmental Protection Agency. Washington, DC. 2009.

[15] Ji, H., \& Khurana Hershey, G. K. (2012). Genetic and epigenetic influence on the response to environmental particulate matter. Journal of Allergy and Clinical Immunology, 129(1), 33-41. doi:10.1016/j.jaci.2011.11.008.

[16] Hulin, M., Simoni, M., Viegi, G., \& Annesi-Maesano, I. (2012). Respiratory health and indoor air pollutants based on quantitative exposure assessments. European Respiratory Journal, 40(4), 1033-1045. doi:10.1183/09031936.00159011.

[17] Romieu, I., Riojas-Rodríguez, H., Marrón-Mares, A. T., Schilmann, A., Perez-Padilla, R., \& Masera, O. (2009). Improved Biomass Stove Intervention in Rural Mexico. American Journal of Respiratory and Critical Care Medicine, 180(7), 649-656. doi:10.1164/rccm.200810-1556oc.

[18] Dominici, F., Peng, R. D., Bell, M. L., Pham, L., McDermott, A., Zeger, S. L., \& Samet, J. M. (2006). Fine Particulate Air Pollution and Hospital Admission for Cardiovascular and Respiratory Diseases. JAMA, 295(10), 1127. doi:10.1001/jama.295.10.1127.

[19] Tielsch, J. M., Katz, J., Zeger, S. L., Khatry, S. K., Shrestha, L., Breysse, P., ... LeClerq, S. C. (2014). Designs of two randomized, community-based trials to assess the impact of alternative cookstove installation on respiratory illness among young children and reproductive outcomes in rural Nepal. BMC Public Health, 14(1). doi:10.1186/1471-2458-14-1271.

[20] Tielsch, J. M., Steinhoff, M., Katz, J., Englund, J. A., Kuypers, J., Khatry, S. K., ... LeClerq, S. C. (2015). Designs of two randomized, community-based trials to assess the impact of influenza immunization during pregnancy on respiratory illness among pregnant women and their infants and reproductive outcomes in rural Nepal. BMC Pregnancy and Childbirth, 15(1). doi:10.1186/s12884-015-0470-y.

[21] Kumar, R., Singh, K., Nagar, S., Kumar, M., Mehto, U. K., Rai, G., \& Gupta, N. (2015). Pollutant levels at cooking place and their association with respiratory symptoms in women in a rural area of Delhi-NCR. Indian J Chest Dis Allied Sci, 57(4), 22531. 
[22] Kumar, R., Nagar, J. K., Goel, N., Kumar, P., Kushwah, A. S., \& Gaur, S. N. (2015). Indoor air pollution and asthma in children at Delhi, India. Pneumonologia i Alergologia Polska, 83(4), 275-282. doi:10.5603/piap.2015.0047.

[23] Ezzati, M., \& Kammen, D. M. (2001). Indoor air pollution from biomass combustion and acute respiratory infections in Kenya: an exposure-response study. The Lancet, 358(9282), 619-624. doi:10.1016/s0140-6736(01)05777-4.

[24] Kurmi, O. P., Semple, S., Steiner, M., Henderson, G. D., \& Ayres, J. G. (2008). Particulate matter exposure during domestic work in Nepal. Annals of occupational hygiene, 52(6), 509-517. doi:10.1093/annhyg/men026.

[25] Rumchev, K., Spickett, J. T., Brown, H. L., \& Mkhweli, B. (2007). Indoor air pollution from biomass combustion and respiratory symptoms of women and children in a Zimbabwean village. Indoor Air, 0(0), 071105095528002-??? doi:10.1111/j.1600-0668.2007.00494.x.

[26] World Health Organisation, WHO IAQ guidelines 2014; Household fuel combustion. WHO Geneva.

[27] WHO. Air quality guidelines, global update. http://www.euro.who.int/Document/E90038.pdf 2006 (accessed April 2018). 